\title{
Research Article \\ Controlling Chaos in Permanent Magnet Synchronous Motor Control System via Fuzzy Guaranteed Cost Controller
}

\author{
Yi-You Hou \\ Department of Electrical Engineering, Far East University, Tainan 74448, Taiwan \\ Correspondence should be addressed to Yi-You Hou, hou.yi_you@msa.hinet.net
}

Received 14 April 2012; Revised 18 June 2012; Accepted 4 July 2012

Academic Editor: Stefan Siegmund

Copyright (C) 2012 Yi-You Hou. This is an open access article distributed under the Creative Commons Attribution License, which permits unrestricted use, distribution, and reproduction in any medium, provided the original work is properly cited.

This paper investigates the guaranteed cost control of chaos problem in permanent magnet synchronous motor (PMSM) via Takagi-Sugeno (T-S) fuzzy method approach. Based on Lyapunov stability theory and linear matrix inequality (LMI) technique, a state feedback controller is proposed to stabilize the PMSM systems. An illustrative example is provided to verify the validity of the results developed in this paper.

\section{Introduction}

The permanent magnet synchronous motor (PMSM) is an important role in industrial applications due to its simple structure, high efficiency, high power density, and low maintenance cost [1-3]. However, the dynamic characteristics and stability analysis of PMSM has emerged as a new and attractive research field, such as bifurcation, chaos, and limit cycle dynamic behaviors [4-9]. Moreover, many profound theories and methodologies [10-16] have been developed to deal with this issue. In [4], the adaptive dynamic surface control (DSC) of PMSM has been presented. In [5, 6], the authors had derived some feedback control design methods for stability of PMSM in their results. Some control methods had studied to stabilize the PMSM systems, such as sliding mode control (SMC) [7], differential geometry method [8], passivity control [9, 10], sensorless control [11-14], Lyapunov exponents (LEs) placement [15], and fuzzy control [16].

Takagi-Sugeno (T-S) fuzzy concept was introduced by the pioneering work of Takagi and Sugeno [17] and has been successfully and effectively used in complex nonlinear systems [18]. The main feature of T-S fuzzy model is that a nonlinear system can be approximated by a set of T-S linear models. The overall fuzzy model of complex nonlinear systems is achieved by fuzzy "blending" of the set of T-S linear models. Therefore, the controller design and the 
stability analysis of nonlinear systems can be analyzed via T-S fuzzy models and the so-called parallel distributed compensation (PDC) scheme $[19,20]$.

This paper contributes to the development of the state-feedback control design for PMSM. Based on Lyapunov stability theory and LMI technique, the stability conditions of PMSM are analyzed. Finally, an example is given to illustrate the usefulness of the obtained results.

\section{Problem Formulation and Main Results}

Based on $d-q$ axis, the dynamics of permanent synchronous motor plant can be described by the following differential equation [15]:

$$
\begin{aligned}
& \frac{d i_{d}}{d t}=\frac{u_{d}-R_{1} i_{d}+w L_{q} i_{q}}{L_{d}} \\
& \frac{d i_{q}}{d t}=\frac{u_{q}-R_{1} i_{q}+w L_{q} i_{q}-w \psi_{r}}{L_{q}} \\
& \frac{d w}{d t}=\frac{n_{p} \psi_{r} i_{q}+n_{p}\left(L_{d}-L_{q}\right) i_{d} i_{q}-T_{L}-\beta w}{J}
\end{aligned}
$$

where $i_{d}, i_{q}$, and $w$ are state variables, which denote $d, q$ axis stator currents, and $w$ is motor angular speed, respectively. $T_{L}, u_{d}$, and $u_{q}$ are the external load torque, the direct- and quadrature-axis stator voltage components, respectively. $J$ is the polar moment of inertia, $\beta$ is the viscous damping coefficient, $R_{1}$ is the stator winding resistance, and $L_{d}$ and $L_{q}$ are the direct- and quadrature-axis stator inductors, respectively. $\psi_{r}$ is the permanent magnet flux, and $n_{p}$ is the number of pole pairs. By applying the affine transformation $x=\lambda \tilde{x}$, $t=\tau \tilde{t}, x=\left[\begin{array}{lll}i_{d} & i_{q} & w\end{array}\right]^{T}, \tilde{x}=\left[\begin{array}{lll}\tilde{i}_{d} & \tilde{i}_{q} & \widetilde{w}\end{array}\right]^{T}, b=L_{q} / L_{d}, k=\beta /\left(n_{p} \tau \psi_{r}\right), \tau=L_{q} / R$, and $\lambda=\operatorname{diag}\left[\begin{array}{lll}\lambda_{d} & \lambda_{q} & \lambda_{w}\end{array}\right]=\operatorname{diag}\left[\begin{array}{lll}b k & k & 1 / \tau\end{array}\right]$, system (2.1) can be transformed as follows:

$$
\begin{aligned}
& \frac{d \tilde{i}_{d}}{d t}=-\tilde{i}_{d}+\tilde{i}_{q} \tilde{w}+\tilde{u}_{d}, \\
& \frac{d \tilde{i}_{q}}{d t}=-\tilde{i}_{q}-\tilde{i}_{d} \tilde{w}+\gamma \tilde{w}+\tilde{u}_{q}, \\
& \frac{d \tilde{w}}{d t}=\sigma\left(\tilde{i}_{q}-\tilde{w}\right)-\tilde{T}_{L},
\end{aligned}
$$

where $\tilde{u}_{d}=u_{d} / k R, \gamma=-\psi_{r} / k L_{q}, \tilde{u}_{q}=u_{q} / k R, \sigma=\beta \tau / J$, and $\tilde{T}_{L}=\tau^{2} T_{L} / J$. 
In the system (2.2), the external inputs are set to zero, namely, $\widetilde{T}_{L}=\tilde{u}_{d}=\tilde{u}_{q}=0$. Then, the system (2.2) becomes

$$
\begin{aligned}
& \frac{d \tilde{i}_{d}}{d t}=-\tilde{i}_{d}+\tilde{i}_{q} \tilde{w}, \\
& \frac{d \tilde{i}_{q}}{d t}=-\widetilde{i}_{q}-\tilde{i}_{d} \widetilde{w}+\gamma \widetilde{w}, \\
& \frac{d \tilde{w}}{d t}=\sigma\left(\tilde{i}_{q}-\tilde{w}\right),
\end{aligned}
$$

or

$$
\begin{aligned}
& \dot{x}_{1}(t)=-x_{1}(t)+x_{2}(t) x_{3}(t), \\
& \dot{x}_{2}(t)=-x_{2}(t)-x_{1}(t) x_{3}(t)+\gamma \cdot x_{3}(t), \\
& \dot{x}_{3}(t)=\sigma \cdot\left[x_{1}(t)-x_{3}(t)\right],
\end{aligned}
$$

where $x_{1}=\widetilde{i}_{d}, x_{2}=\widetilde{i}_{q}, x_{3}=\tilde{w}$.

To investigate the control design of system (2.4), let the system's state vector $x(t)=$ $\left[\begin{array}{lll}x_{1} & x_{2} & x_{3}\end{array}\right]^{T}$ and the control input vector be $u(t)$. Then, the state equations of PMSM can be represented as follows:

$$
\dot{x}(t)=A(x(t)) x(t)+B u(t),
$$

where $x(t)=\left[\begin{array}{lll}x_{1}(t) & x_{2}(t) & x_{3}(t)\end{array}\right]^{T}, A(x(t))=\left[\begin{array}{ccc}-1 & x_{3}(t) & 0 \\ -x_{3}(t) & -1 & \gamma \\ 0 & \sigma & -\sigma\end{array}\right]$.

The continuous fuzzy system was proposed to represent a nonlinear system [17]. The system dynamics can be captured by a set of fuzzy rules which characterize local correlations in the state space. Each local dynamic described by the fuzzy IF-THEN rule has the property of linear input-output relation. Based on the T-S fuzzy model concept, the nonlinear PMSM system can be expressed as follows.

Model rule $i$ :

If $z_{1}(t)$ is $M_{i 1}$ and $\cdots z_{r}(t)$ is $M_{i r}$, then

$$
\dot{x}(t)=A_{i} x(t)+B_{i} u(t)
$$

where $z_{1}(t), z_{2}(t), \ldots, z_{r}(t)$ are known premise variables, $M_{i j}, i \in\{1,2, \ldots, m\}, j \in\{1,2, \ldots, r\}$ is the fuzzy set, and $m$ is the number of model rules; $x(t)$ is the state vector, and $u(t)$ is input 
vector. The matrices $A_{i}$ and $B$ are known constant matrices with appropriate dimensions. Given a pair of $(x(t), u(t))$, the final outputs of the fuzzy system are inferred as follows:

$$
\begin{aligned}
\dot{x}(t) & =\frac{\sum_{i=1}^{m} w_{i}(z(t)) \cdot\left\{A_{i} x(t) B_{i} u(t)\right\}}{\sum_{i=1}^{m} w_{i}(z(t))} \\
& =\sum_{i=1}^{m} \eta_{i}(z(t)) \cdot\left\{A_{i} x(t)+B_{i} u(t)\right\},
\end{aligned}
$$

where $z(t)=\left[\begin{array}{llll}z_{1}(t) & z_{2}(t) & \cdots & z_{r}(t)\end{array}\right], w_{i}(z(t))=\prod_{j=1}^{r} M_{i j}\left(z_{j}(t)\right), \eta_{i}(z(t))=w_{i}(z(t)) /$ $\sum_{i=1}^{m} w_{i}(z(t))$. The term $M_{i j}\left(z_{j}(t)\right)$ is the grade of membership of $z_{j}(t)$ in $M_{i j}$. In this paper, we assume that $w_{i}(z(t)) \geq 0, i \in\{1,2, \ldots, m\}$, and $\sum_{i=1}^{m} w_{i}(z(t))>0$. Therefore, we have $\eta_{i}(z(t)) \geq 0, i \in\{1,2, \ldots, m\}$ and $\sum_{i=1}^{m} \eta_{i}(z(t))=1$, for all $t \geq 0$.

To derive the main results, we first introduce the cost fuction of system (2.4) as follows:

$$
J=\int_{0}^{\infty}\left[x^{T}(s) \cdot S_{1} \cdot x(s)+u^{T}(s) \cdot S_{2} \cdot u(s)\right] d s
$$

where $S_{1}$ and $S_{2}$ are two given positive definite symmetric matrices with appropriate dimensions. Associated with cost function (2.8), the fuzzy guaranteed cost control is defined as follows.

Definition 2.1 (see [21]). Consider the T-S fuzzy PMSM system (2.6); if there exist a control law $u(t)$ and a positive scalar $J^{*}$ such that the closed-loop system is stable and the value of cost function (2.8) satisfies $J \leq J^{*}$, then $J^{*}$ is said to be a guaranteed cost and $u(t)$ is said to be a guaranteed cost control law for the T-S fuzzy PMSM system (2.6).

This paper aims at designing a guaranteed cost control law for the asymptotic stabilization of the T-S fuzzy PMSM system (2.6). To achieve this control goal, we utilize the concept of PDC [17] scheme and select the fuzzy guaranteed cost controller via state feedback as follows.

Control rule $j$ :

If $z_{1}(t)$ is $M_{j 1}$ and $\cdots z_{r}(t)$ is $M_{j r}$, then

$$
u(t)=-K_{j} x(t), \quad t \geq 0, j=\{1,2, \ldots, m\},
$$

where $K_{j}, j \in\{1,2, \ldots, m\}$ are the state feedback gains. Hence, the overall state feedback control law is represented as follows:

$$
u(t)=-\sum_{j=1}^{m} \eta_{j}(z(t)) \cdot K_{j} x(t), \quad t \geq 0 .
$$

Before proposing the main theorem for determining the feedback gains $K_{j}(j=$ $1,2, \ldots, m)$, a lemma is introduced.

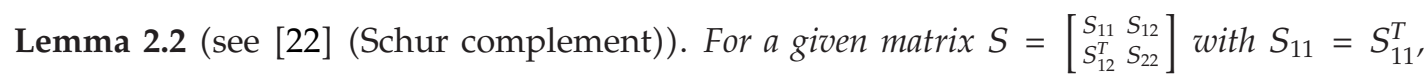
$S_{22}=S_{22}^{T}$, then the following conditions are equivalent: 
(1) $S<0$,

(2) $S_{22}<0, S_{11}-S_{12} S_{22}^{-1} S_{12}^{T}<0$.

Now we present a asymptotic stabilization condition for T-S fuzzy PMSM system (2.6).

Theorem 2.3. If there exist some positive definite symmetric matrices $\bar{P}$ and matrices $\widehat{K}_{j}, j \in$ $\{1,2, \ldots, m\}$ such that the following $L M I$ condition holds for all $i, j \in\{1,2, \ldots, m\}$ :

$$
\tilde{\Phi}_{i j}=\left[\begin{array}{ccc}
A_{i} \bar{P}+\bar{P} A_{i}^{T}-B_{i} \widehat{K}_{j}-\widehat{K}_{j}^{T} B_{i}^{T} & \bar{P} & \widehat{K}_{j}^{T} \\
* & -S_{1}^{-1} & 0 \\
* & * & -S_{2}^{-1}
\end{array}\right]<0,
$$

then system (2.6) is asymptotically stabilizable by controller (2.10). The stabilizing feedback control gain is given by $K_{j}=\widehat{K}_{j} \bar{P}^{-1}$, and the system performance (2.8) is bounded by

$$
J \leq J^{*}=x^{T}(0) P x(0),
$$

where $P=\bar{P}^{-1}$.

Proof. Define the Lyapunov functional

$$
V\left(x_{t}\right)=x^{T}(t) P x(t)
$$

where $V\left(x_{t}\right)$ is a legitimate Lyapunov functional candidate, and $P$ is positive definte symmetric matrices. By the system (2.6) with $\sum_{i=1}^{m} \eta_{i}(z(t))=1$, the time derivatives of $V\left(x_{t}\right)$, along the trajectories of system (2.6) with (2.8) and (2.10), satisfy

$$
\begin{aligned}
& \dot{V}\left(x_{t}\right)-\sum_{i=1}^{m} \sum_{j=1}^{m} \eta_{i}(z(t)) \eta_{j}(z(t)) x^{T}(t)\left(S_{1}+K_{j}^{T} S_{2} K_{j}\right) x(t) \\
& =\sum_{i=1}^{m} \sum_{j=1}^{m} \eta_{i}(z(t)) \eta_{j}(z(t)) x^{T}(t)\left(P A_{i}+A_{i}^{T} P-K_{j}^{T} B_{i}^{T} P-P B_{i} K_{j}\right) x(t) \\
& =\sum_{i=1}^{m} \sum_{j=1}^{m} \eta_{i}(z(t)) \eta_{j}(z(t)) x^{T}(t)\left(P A_{i}+A_{i}^{T} P-K_{j}^{T} B_{i}^{T} P-P B_{i} K_{j}+S_{1}+K_{j}^{T} S_{2} K_{j}\right) x(t) \\
& \leq \sum_{i=1}^{m} \sum_{j=1}^{m} \eta_{i}(z(t)) \eta_{j}(z(t)) x^{T}(t) \Phi_{i j} x(t) .
\end{aligned}
$$


In order to guarantee $\dot{V}\left(x_{t}\right)-\sum_{i=1}^{m} \sum_{j=1}^{m} \eta_{i}(z(t)) \eta_{j}(z(t)) x^{T}(t)\left(S_{1}+K_{j}^{T} S_{2} K_{j}\right) x(t)<0$, we need to satisfy $\Phi_{i j}<0$. By Lemma 2.2, premultiplying, and postmultiplying the $\Phi_{i j}$ in (2.14) by $P^{-1}>0, \Phi_{i j}<0$ are equivalent to $\widetilde{\Phi}_{i j}<0$ in (2.11), then we can obtain the following:

$$
\begin{aligned}
\dot{V}\left(x_{t}\right) & \leq-\sum_{i=1}^{m} \sum_{j=1}^{m} \eta_{i}(z(t)) \eta_{j}(z(t)) x^{T}(t)\left(S_{1}+K_{j}^{T} S_{2} K_{j}\right) x(t) \\
& =-\left(x^{T}(t) \cdot S_{1} \cdot x(t)+u(t) \cdot S_{2} \cdot u(t)\right)<0 .
\end{aligned}
$$

From the inequality (2.15), $\dot{V}\left(x_{t}\right)<0$, we conclude that system (2.6) with (2.8) is asymptotically stable. Integrating (2.12) from 0 to $\infty$, we have

$$
\int_{0}^{\infty} \dot{V}\left(x_{s}\right) d s=\lim _{t \rightarrow \infty} V\left(x_{t}\right)-V\left(x_{0}\right) \leq-\int_{0}^{\infty}\left[x^{T}(s) \cdot S_{1} \cdot x(s)+u^{T}(s) \cdot S_{2} \cdot u(s)\right] d s
$$

Since that the system (2.6) with (2.8) is asymptotically stable, we can obtain the following results:

$$
\lim _{t \rightarrow \infty} V\left(x_{t}\right)=0
$$

Consequently, $J=\int_{0}^{\infty}\left[x^{T}(s) \cdot S_{1} \cdot x(s)+u^{T}(s) \cdot S_{2} \cdot u(s)\right] d s \leq x^{T}(0) P x(0)=V\left(x_{0}\right)=J^{*}$. This completes the proof.

\section{Numerical Simulation and Analysis}

In this section, a numerical example is presented to demonstrate and verify the performance of the proposed results. Consider a PMSM as given in (2.1) with the following parameters [23]: $L_{d}=L_{q}=L=14.25 \mathrm{mH}, R_{1}=0.9 \Omega, \psi_{r}=0.031 \mathrm{Nm} / \mathrm{A}, n_{p}=1, J=4.7 \times 10^{-5} \mathrm{~kg} \mathrm{~m}^{2}$, $\beta=0.0162 \mathrm{~N} / \mathrm{rad}, \gamma=20$, and $\sigma=5.46$.

From the simulation result, we can get that $x_{3}(t)$ is bounded in interval [ -1212$]$. By solving the equation, $M_{1}$ and $M_{2}$ are obtained as follows:

$$
M_{1}\left(x_{3}(t)\right)=\frac{1}{2}\left(1+\frac{x_{3}(t)}{d}\right), \quad M_{2}\left(x_{3}(t)\right)=1-M_{1}\left(x_{3}(t)\right)=\frac{1}{2}\left(1-\frac{x_{3}(t)}{d}\right) .
$$

$M_{1}$ and $M_{2}$ can be interpreted as membership functions of fuzzy sets. Using these fuzzy sets, the nonlinear system with time-varying delays can be expressed by the following T-S fuzzy models.

Rule 1. IF $x_{3}(t)$ is $M_{1}$, then

$$
\dot{x}(t)=A_{1} x(t)+B_{1} u(t) .
$$




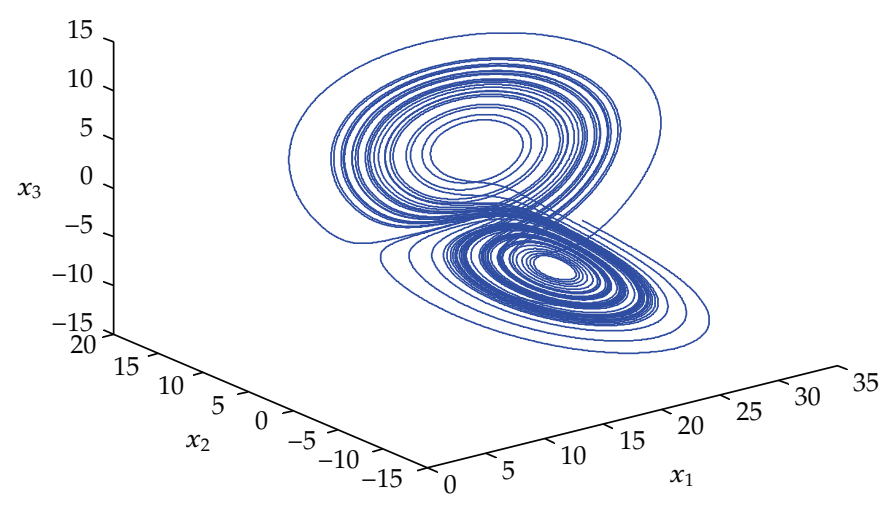

Figure 1: The chaotic attractor of the PMSM system.

Rule 2. IF $x_{3}(t)$ is $M_{2}$, then

$$
\dot{x}(t)=A_{2} x(t)+B_{2} u(t)
$$

where

$$
\begin{array}{cc}
x(t)=\left[\begin{array}{ccc}
x_{1}(t) & x_{2}(t) & x_{3}(t)
\end{array}\right]^{T}, \quad A_{1}=\left[\begin{array}{ccc}
-1 & -12 & 0 \\
12 & -1 & 20 \\
5.46 & 0 & -5.46
\end{array}\right], \\
A_{2}=\left[\begin{array}{ccc}
-1 & 12 & 0 \\
-12 & -1 & 20 \\
5.46 & 0 & -5.46
\end{array}\right], \quad B_{1}=B_{2}=\left[\begin{array}{l}
0 \\
0 \\
1
\end{array}\right] .
\end{array}
$$

By the theorem, the stabilizing fuzzy control gains are given by $K_{1}=K_{2}=$ [3.968 19.902 77.990].

Consequently, the minimal guaranteed cost is $J^{*}=5.443 \times 10^{-11}$. The simulation was done with a four-order Runge-Kutta integration algorithm in MATLAB 7 with a step size of 0.0001 . The simulation results with initial conditions $x(0)=[13.5-5-5]^{T}$ are shown in Figures 1-2. The chaotic attractor of PMSM system is given in Figure 1. The frequency power spectrum of the PMSM system variables is illustrated in Figure 2. The system state responses trajectory of controller design is shown in Figure 3. Figure 4 depicts the time responses of the control input of $u(t)$. When $t=20 \mathrm{sec}$, it is obvious that the feedback control gain can guarantee stability of PMSM systems. From the simulation results, it is shown that the proposed controller works well to guarantee stability.

\section{Conclusion}

We have presented the solutions to the guaranteed cost control of chaos problem via the Takagi-Sugeno fuzzy control for PMSM system. Based on Lyapunov stability theory and LMI technique, the guaranteed cost control gains can be easily obtained through a convex 


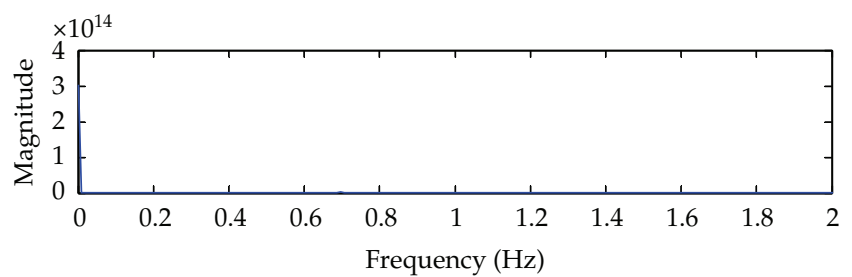

(a)

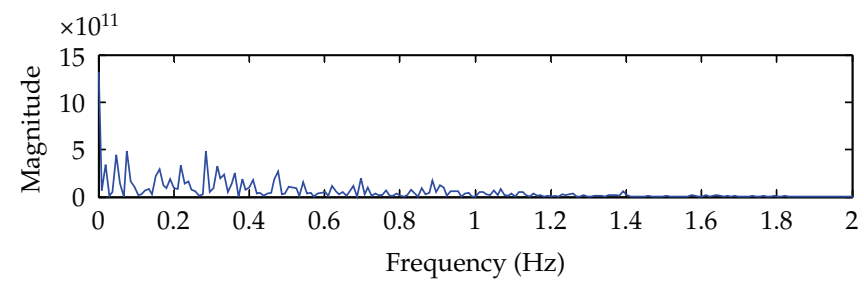

(b)

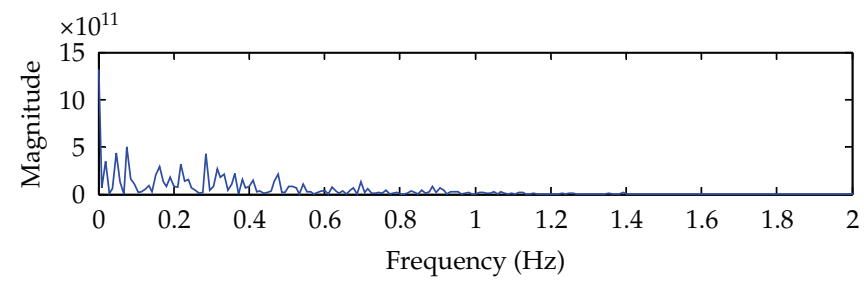

(c)

Figure 2: Power spectrum of the state variables $x_{1}(t), x_{2}(t)$, and $x_{3}(t)$ of the PMSM system.
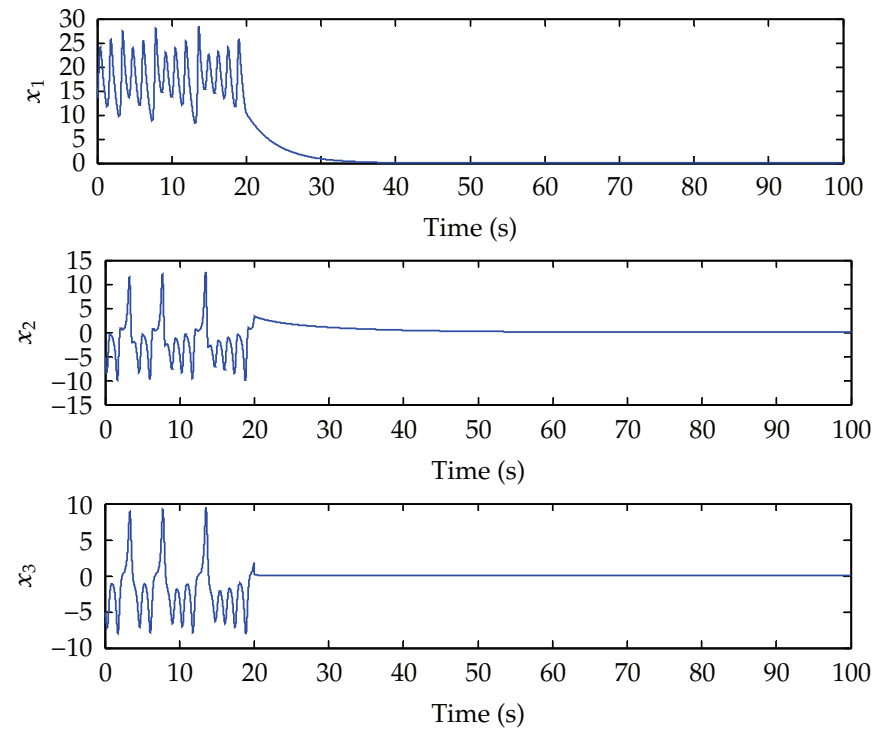

Figure 3: The state responses of the controlled PMSM system. 


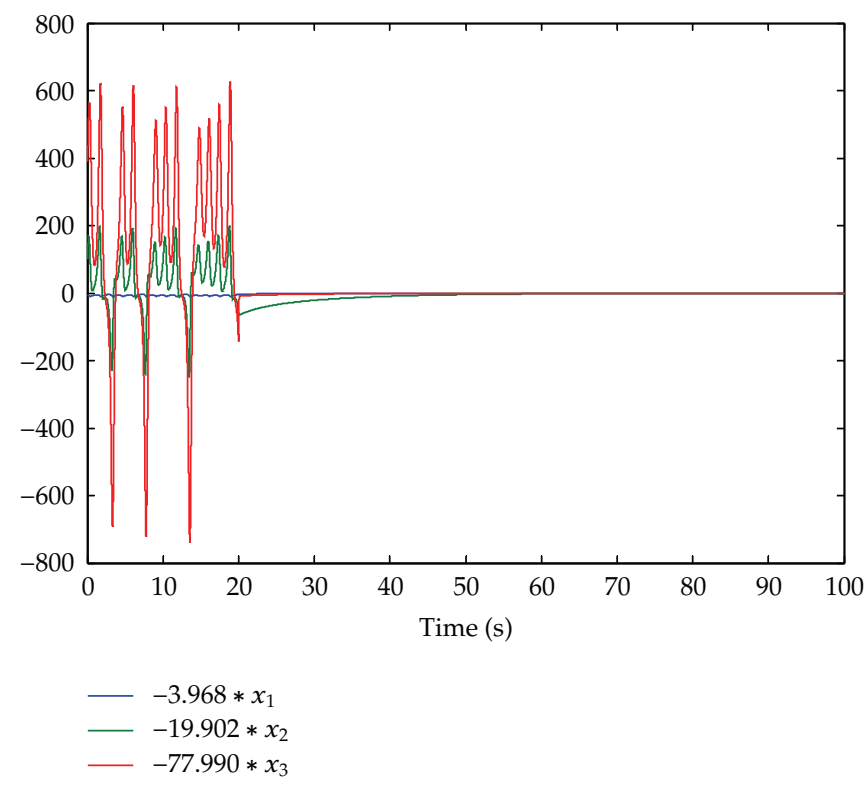

Figure 4: Time response of control input $u(t)$.

optimization problem. Finally, a numerical example shows the validity and superiority of the developed result. The future work will extend the proposed method to the underlying systems with noise and disturbances effects, like noise or disturbances, uncertainties effects, and robustness to time-varying delays. Also, the future application in the experiment will be included.

\section{Acknowledgments}

The author thanks the National Science Council of Taiwan for supporting this work under Grant NSC 101-2622-E-269-012-CC3. The author also wishes to thank the anonymous reviewers for providing constructive suggestions.

\section{References}

[1] C. Rossi and A. Tonielli, "Robust control of permanent magnet motors: VSS techniques lead to simple hardware implementations," IEEE Transactions on Industrial Electronics, vol. 41, no. 4, pp. 451-460, 1994.

[2] R. Krishnan, Electric Motor Drives, Modeling, Analysis, and Control, Prentice Hall, 2001.

[3] Z. Xu and M. F. Rahman, "Direct torque and flux regulation of an IPM synchronous motor drive using variable structure control approach," IEEE Transactions on Power Electronics, vol. 22, no. 6, pp. 2487-2498, 2007.

[4] D. Q. Wei, X. S. Luo, B. H. Wang, and J. Q. Fang, "Robust adaptive dynamic surface control of chaos in permanent magnet synchronous motor," Physics Letters, Section A, vol. 363, no. 1-2, pp. 71-77, 2007.

[5] Y. Luo, "Current rate feedback control of chaos in permanent magnet synchronous motor," in Proceeding of the CSU-EPSA, vol. 18, no. 6, pp. 31-34, 2006.

[6] H. Ren and D. Liu, "Nonlinear feedback control of chaos in permanent magnet synchronous motor," IEEE Transactions on Circuits and Systems II: Express Briefs, vol. 53, no. 1, pp. 45-50, 2006. 
[7] M. Reichhartinger and M. Horn, "Sliding-mode control of a permenet-magnet synchronous motor with uncertainty estimation," International Journal of Mechanical and Materials Engineering, vol. 1, no. 2, pp. 121-124, 2010.

[8] D. Q. Wei, X. S. Luo, J. Q. Fang, and B. H. Wang, "Controlling chaos in permanent magnet synchronous motor based on the differential geometry method," Acta Physica Sinica, vol. 55, no. 1, pp. 54-59, 2006.

[9] D. L. Qi, J. J. Wang, and G. Z. Zhao, "Passive control of permanent magnet synchronous motor chaotic systems," Journal of Zhejiang University, vol. 6, no. 7, pp. 728-732, 2005.

[10] Z. Q. Wu and F. X. Tan, "Passivity control of permanent-magnet synchronous motors chaotic system," Proceedings of the Chinese Society of Electrical Engineering, vol. 26, no. 18, pp. 159-163, 2006.

[11] N. Ertugrul and P. Acarnley, "New algorithm for sensorless operation of permanent magnet motors," IEEE Transactions on Industry Applications, vol. 30, no. 1, pp. 126-133, 1994.

[12] M. M. Hussein, M. Orabi, M. E. Ahmed, M. A. Abd El-Wahab, and M. M. Hamada, "Simple direct sensorless control of permanent magnet synchronous generator wind turbine," in Proceedings of the 14th International Middle East Power Systems Conference (MEPCON'10), paper ID 257, pp. 19-21, Cairo University, Egypt, 2010.

[13] O. Wallmark and L. Harnefors, "Sensorless control of salient PMSM drives in the transition region," IEEE Transactions on Industrial Electronics, vol. 53, no. 4, pp. 1179-1187, 2006.

[14] J. K. Seok, J. K. Lee, and D. C. Lee, "Sensorless speed control of nonsalient permanent-magnet synchronous motor using rotor-position-tracking PI controller," IEEE Transactions on Industrial Electronics, vol. 53, no. 2, pp. 399-405, 2006.

[15] M. Ataei, A. Kiyoumarsi, and B. Ghorbani, "Control of chaos in permanent magnet synchronous motor by using optimal Lyapunov exponents placement," Physics Letters, Section A, vol. 374, no. 41, pp. 4226-4230, 2010.

[16] Y. Shen, Y. Zhou, and Z. Ji, “Fuzzy guaranteed cost control of permanent magnet synchronous motor chaos systems via fuzzy Pl lyapunov function approach," in Proceedings of the 2 nd IEEE Conference on Industrial Electronics and Applications (ICIEA'07), pp. 2449-2454, May 2007.

[17] T. Takagi and M. Sugeno, "Fuzzy identification of systems and its applications to modeling and control," IEEE Transactions on Systems, Man and Cybernetics, vol. 15, no. 1, pp. 116-132, 1985.

[18] H. Han, C. Y. Su, and S. Murakami, "Adaptive fuzzy control for a class of discrete-time nonlinear systems," in Proceedings of the 10th IEEE International Conference on Fuzzy Systems, pp. 892-895, December 2001.

[19] K. Tanaka, "Stability and stabilizability of fuzzy-neural-linear control systems," IEEE Transactions on Fuzzy Systems, vol. 3, no. 4, pp. 438-447, 1995.

[20] H. O. Wang, K. Tanaka, and M. F. Griffin, "An approach to fuzzy control of nonlinear systems: stability and design issues," IEEE Transactions on Fuzzy Systems, vol. 4, no. 1, pp. 14-23, 1996.

[21] K. Tanaka and H. O. Wang, Fuzzy Control Systems Design and Analysis, John Wiley \& Sons, New York, NY, USA, 2001.

[22] S. Boyd, L. El Ghaoui, E. Feron, and V. Balakrishnan, Linear Matrix Inequalities in System and Control Theory, vol. 15 of SIAM Studies in Applied Mathematics, SIAM, Philadelphia, Pa, USA, 1994.

[23] Z. Li, J. B. Park, Y. H. Joo, B. Zhang, and G. Chen, "Bifurcations and chaos in a permanent-magnet synchronous motor," IEEE Transactions on Circuits and Systems I, vol. 49, no. 3, pp. 383-387, 2002. 


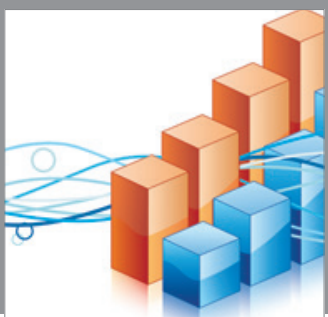

Advances in

Operations Research

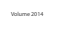

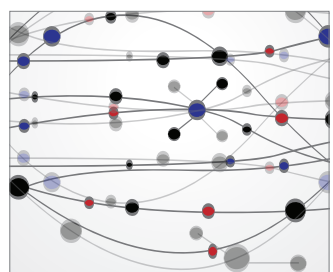

\section{The Scientific} World Journal
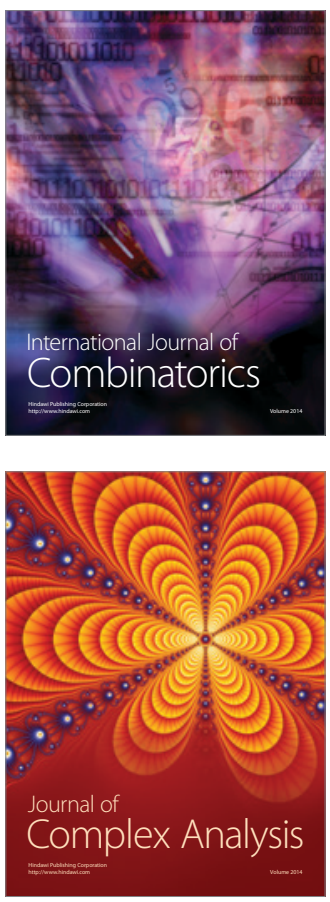

International Journal of

Mathematics and

Mathematical

Sciences
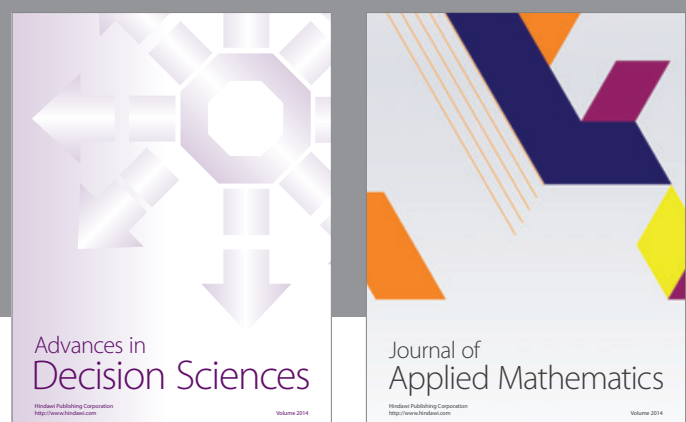

Journal of

Applied Mathematics
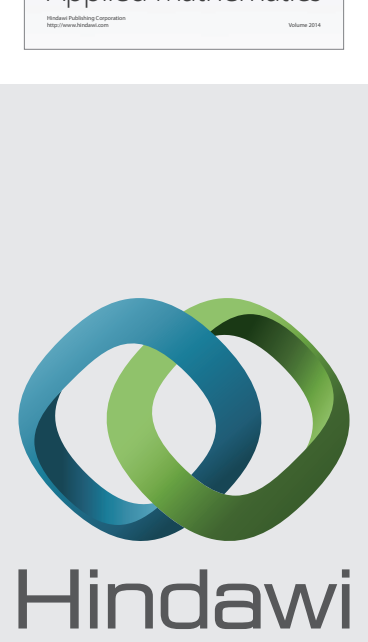

Submit your manuscripts at http://www.hindawi.com
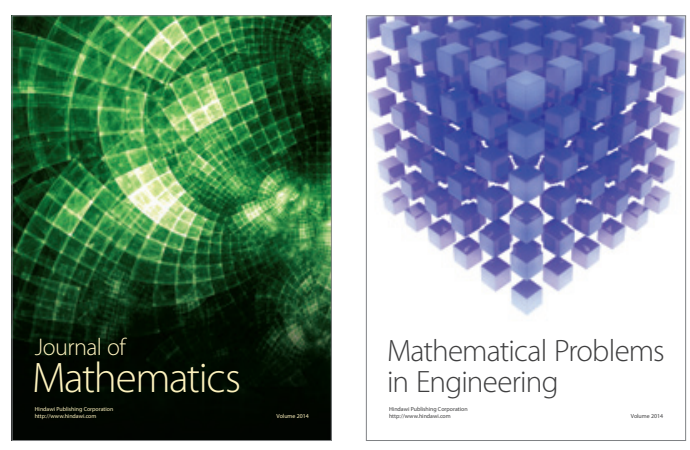

Mathematical Problems in Engineering
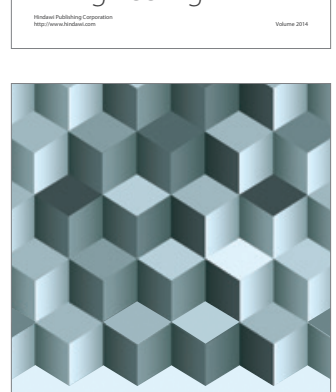

Journal of

Function Spaces
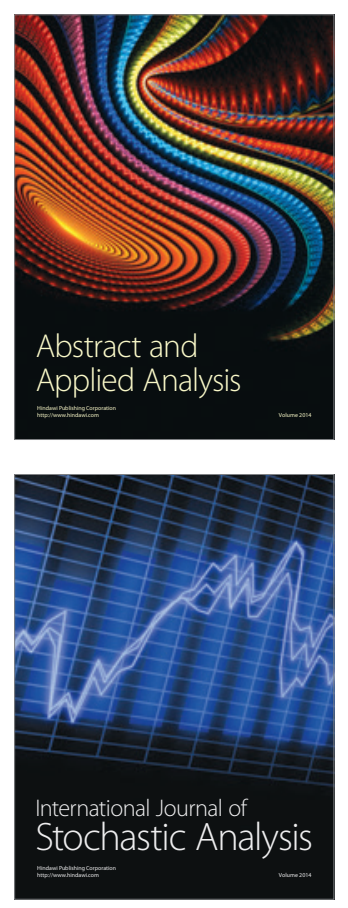

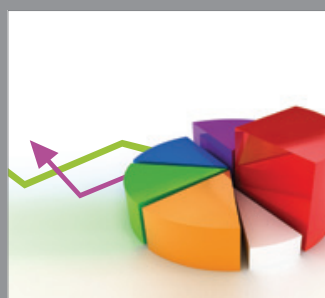

ournal of

Probability and Statistics

Promensencen
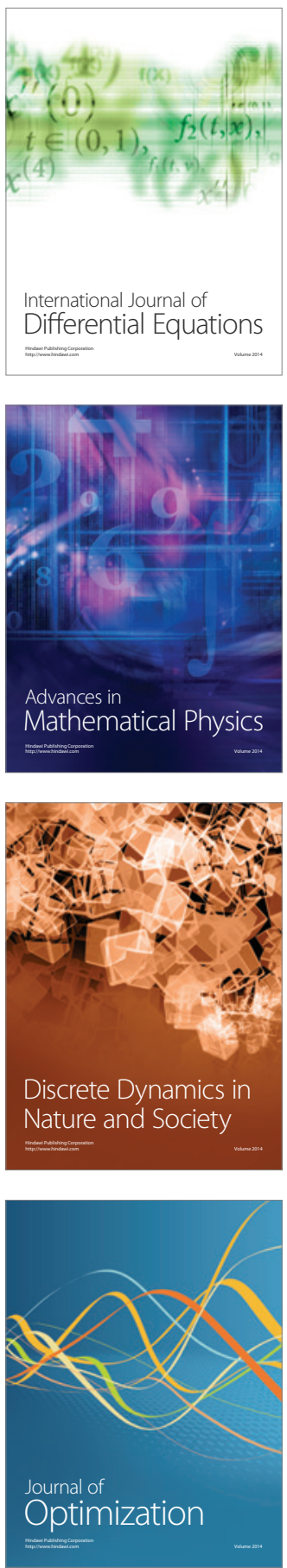